EESTI NSV TEADUSTE AKADEEMIA TOIMETISED 1953. II k., nr. 1 ИЗВЕСТИЯ АКАДЕМИИ НАУК ЭСТОНСКОИ ССР 1953. ТоМ II, № I

\title{
РАЗВИТИЕ ОСНОВНЫХ АСТРОНОМО-ГЕОДЕЗИЧЕСКИХ РАБОТ НА ТЕРРИТОРИИ ЭСТОНСКОИ ССР В ПЕРИОД 1811-1940 ГГ.
}

\author{
Г. А. ЖЕЛНИН, \\ кандидат физико-математических наук
}

Триангуляция, как способ определения опорных пунктов при картографировании страны, вошла в геодезическую практику России сравнительно поздно, в начале ХІХ столетия. Эта кажущаяся недооценка метода трнангулящии имеет, однако, свон глубокие причины. В картографировании страны, мало изученной, мало исследованной, какою была тогдашняя Россия, огромной по велнчине, стояла первоочередная задача составление генеральной карты всей ее территории. Петр I, глубоко осознавший необходимость и важность составления государственной карты, строго и последовательно подходит к выполнению этой задачи. Подготовляются кадры, составляется инструкция. Контроль и наблюдение за работами возлагаются на Сенат. Составлением генеральной карты и атласа России руководит Географический департамент созданной Петром I Академии наук. Опорные пункты определяются астрономически. В условиях мелкомасштабного картографирования метод триангуляции себя, конечно, не оправдал бы. В 1745 году был издан «Атлас Российский». Интересно привести слова известного математика Эйлера, члена Российской Академии наук, в связи с нзданием атласа: «География России приведена была гораздо в исправнейшее состояние, нежели география Немецкой земли». По количеству астрономически определенных опорных пунктов Россия выходит на первое место среди стран Европы. После издания атласа картографирование продолжается. Академией наук организуются специальные астрономические экспедищни. К 1789 году насчитывается 67 точно определенных астрономических пунктов. Большая заслуга в картографировании страны принадлежит великому русскому ученому М. В. Ломоносову, возглавлявшему с 1757 по 1765 год Географический департамент Академии наук.

С выполнением первоочередной задачи - составления генеральной карты России, настала очередь детальному картографированию страны. Первыми объектами детального картографирования становятся районы, примыкающие к тогдашней столице и окаймляющие берега Финского залива - этого коридора к «окну в Европу». Поэтому не случайно, что первые геодезические работы развертываются именно на территории теперешней Әстонской ССР. Не случайно также, что именио территория Эстонской ССР явилась свндетельницей возрождения и стремительного роста геодезической мысли и практики в России.

На этой территории начали свою работу замечательные геодезисты 
начала XIX века Струве, Теннер и Шуберт; на этой же территории зародилось величайшее геодезическое начинание XIX столетия - градусное измерение вдоль мередиана, длиною $25^{\circ} 20^{\prime}$, от Северного Ледовитого океана до Дуная. По водам Балтийского моря и Фннского залива впервые проводились хронометрические экспедиции для определения долгот основных пунктов; именно в работах, проведенных здесь, зародились и оформились новые методы и были выработаны приборы, обогатившие геодезическую науку и получившие распространение и широкое применение.

Первые попытки триангуляционных работ в России относятся к 1737 году, когда первый астроном Академии наук Жозеф Делиль. желая провести в России измерение дуги меридиана, измерил деревянными жезлами по льду Финского залива базис и связал его несколькими треугольниками с близлежащими пунктами. На этом работа и заглохла.

В 1811 году первую по времени русскую триангуляцию видного русского геодезиста ген. Теннера (начата в 1809 году), доведенную к этому времени от Петербурга до Нарвы, предполагалось продолжить вдоль южного побережья Финского залива до г. Ревель (ныне Таллин). К сожаленню, этой работе не суждено было состояться; нахлынувшне события 1812 года приостановили ее.

В Отечественную войну 1812 года выявилась настоятельная потребность в точных картах, в особенности в картах пограничных районов. На проведение геодезических работ обращается особое внимание, организуется Қорпус военных топографов (1822), приступивший к планомерному проведению работ. Наряду с ним обширные геодезическне работы ставятся и другими организащиями.

Основное внимание обращается на западные районы, по которым шли пути вторжения вражеских полчищ в пределы нашей страны. С 1816 года ген. Теннер приступает к триангулящии тогдашних Виленской, Курляндской, Гродненской и Минской губерний. Выполненная здесь замечательная работа явилась частью первого русского градусного измерения.

В то же время развертываются геодезические работы и на территории нынешней Эстонской ССР. Анализ и разбор всех геодезических работ, выполненных на территории Эстонии, дает возможность выделить два периода в постановке и проведении геодезических работ в дореволюционной России; к третьему периоду мы относим работы, проведенные на территории Эстонии в буржуазное время.

Первый период (1816-1858) можно охарактеризовать как период создания геодезической практики, период исканий, совершенствований приемов и инструментария, период обособленных, узких по своим задачам, отдельных работ. К этому периоду относятся: 1) Лифляндская триангуляция (Струве, 1816-1819); 2) Градусное измеренне (Струве, 1821 - 1831); 3) Тригонометрическая съемка губерний С.-Петербургской, Псковской, Витебской и части Новгородской (Шуберт, 1820-1832); 4) Тригонометрическая съемка берегов Балтийского моря (Шуберт, $1830-1838)$; 5) сюда же можно причислить более позднюю по времени Эстляндскую триангуляцию (Злобин, 1856-1858). В кратких чертах остановимся на каждой из перечисленных работ в отдельности.

1) В 1816 году В. Я. Струве, днректор астрономической обсерватории Юрьевского (Тартуского) университета, по предложению Лифлянд- 
ского экономического общества приступает к триангуляцин территории Лифляндии (ныне - северная часть Латвнйской ССР и южная часть Эстонской ССР до параллели г. Пярну). Целью этой работы было обеспечение надежной основой составления карты губернии. Закрытая местность, недостаток в средствах и отсутствие времени заставили профессора В. Я. Струве выбрать метод астрономо-тригонометрического измерения. Работа охватывает территорию Эстонии почти до 59-й параллели.

В центральной части района съемок работы начались от базиса длиною почти в 12,5 км, измеренного по льду озера Виртсъярв. Сплошная сеть треугольников была развита на север до кирки Коэру (10 км западнее ст. Ракке), на запад до г. Вильянди и на юг до г. Якобпилс Латвийской ССР. От г. Риги до г. Пярну, вдоль берега Рижского залива, ввиду сильной залесенности местности, были выполнены только астрономические измерения. Около города Пярну была развита особая триангуляция, состоящая из 24 треугольников, опирающихся на 15 пунктов. Основанием этой триангуляции послужил базис длиною около 2 км, измеренный железною цепью по льду Пярнуского залива. Всего Лифляндской триангулящией было определено 325 пунктов. Исходным пунктом послужила астрономическая обсерватория в г. Тарту.

2) Уже во время осуществления Лифляндской триангуляции у В. Я. Струве зародилась мысль использовать эту работу для проведения небольшого градусного измерения вдоль меридиана г. Тарту в пределах Эстляндской и Лифляндской губерний. С этой целью цепь треугольников была продолжена на север до острова Гогланд, а часть старых пунктов была заменена новыми. Основанием этого ряда от г. Якобпилс на р. Двнне до о. Гогланд в Финском заливе, общим протяжением $3^{\circ} 35^{\prime}$, послужил базис длиною около 4,5 км, измеренный на полях бывших имений Выйвере и Авандусе (ныне район поселка Симуна, Вяйке-Марьяского района). Астрономически были определены конечные пункты этого ряда, а также исходный пункт - Тартуская астрономическая обсерватория.

На территорию Әстонской ССР приходятся 22 пункта этой триангулящии. К сожалению, от этой классической работы, не уступающей по точности современным измерениям, не осталось на месте следов. Долговременные центры были заложены дишь в конечных пунктах этой дуги и на концах измеренного базиса. Из 22 пунктов 6 представляли местные сооружения (кирки Хальяла, Нигула, Коэру и Хельме, башня замка Пылтсама и Тартуская обсерватория), в которых центры определялись промерами от постоянных точек сооружения. За истекшее время часть сооружений была разрушена (замок Пылтсама), часть перестроена (кирка Хальяла), да и другие не могут гарантировать неизменности своего состояния.

Из центров, заложенных на концах базиса, сохранился только восточный, расположенный на окраине поселка Симуна. В 1947 году было найдено основание и западного конца базиса. Гранитный же камень с вделанным центром пропал $\left.{ }^{1}\right)$.

3) Триангуляция ген. Ф. Ф. Шуберта, выполненная в 1820-1832 годах и носящая название «Тригонометрическая съемка губерний С.-Петербургской, Псковской, Витебской и части Новгородской» вклинилась на территорию нынешней Эстонской ССР в северной части прнблизительно до г. Раквере и в южной части до г. Валга, соединившись в этих районах с градусным измерением В. Я. Струве. Эта триангуляция основывалась на трех базнсах, находящихся вне территории Эстонии. За исходный пункт была принята обсерватория Академии наук в Петербурге. 
4) Более обширной работой явилась «Тригонометрическая съемка берегов Балтийского моря», выполненная Ф. Ф. Шубертом в $1830-$ 1838 годах. За начальную точку этой триангулящии была принята обсерватория, построенная в тороде Таллине на горе Ласнамяэ. Работы были начаты измерением бөзиса по льду Таллинского рейда вдоль берега полуострова Виймси. Триангуляция была развита в восточном направлении вдоль берега Финского залива до соединения с градусным измерением В. Я. Струве и вышеописанной триангулящией Ф. Ф. Шуберта. В западном направлении триангуляция захватила острова Монзундского архнпелага и в дальнейшем (1880) была связана с Курляндской триангуляцией Теннера. В северном направлении трнангуляция была перекинута через Финский залив в Финляндию.

Названная триангулящия преследовала цель обеспечения съемки берегов для составления морских карт Финского залива. В триангуляцию были включены все маяки н церкви прибрежной полосы.

5) К первому же периоду отнесем и Эстляндскую триангуляцию, выполненную подполковником Злобиным с 1856 по 1858 год. Начавшаяся в 1855 году топографическая съемка губернии потребовала обеспечения опорными пуктами районов, не охваченных ни Балтийской триангуляцией Ф. Ф. Шуберта, ни Лифляндской триангуляцией В. Я. Струве (территория между Кейла, Мярьяма, Тюри и Раквере). Триангуляция включала 41 треугольник первого класса и 442 треугольника второго и третьего классов. Первоклассная сеть располагалась в виде простых рядов и опиралась на сторону Балтийской триангулящии Шуберта Қейла-Таллин на западе и на сторону градусного измерения Хальяла-Нигула на востоке. Кроме того триапгулящия была проложена и по местам градусного измерения Струве. Последнее было вызвано, по всей вероятности, тем, что за истекшие 30 лет со времени работ В. Я. Струве сигналы развалились и центры, обозначенные гвоздем в свае, грозили погибнуть.

Приведя перечень и краткое описание проведенных работ, остановимся на общей характернстике работ этого пернода.

Сто тридцать лет тому назад на триангулящню смотрели как на подсобную, временную работу, задача которой заключалась в обеспечении опорными точками предстоящей топографической съемкн. Поэтому-то и не закладывались долговременные центры. Центр обозначался гвоздем в свае или, как например в работах В. Я. Струве, гвоздем в пересечении бревен, соединяющих столбы сигнала. Отсутствие долговременных центров - общая черта работ этого периода. Свая с гвоздем сгнивала, исчезала и хоронила навсегда плоды тяжелых и сложных триангуляционных работ.

Вторая особенность работ этого периода - максимальное использование местных сооружений, даже в ущерб требованию соблюдения выгодной фигуры треугольников. Причина этого, повидимому, кроется в ограниченности отпускаемых средств.

Следующей особенностью данных работ является отсутствие единых нормальных мер и обоснование работ на различных, не связанных между собою, исходных пунктах. Это вполне понятно, если учесть отсутствие в то время координирующего геодезического центра. Струве работал по своей инишиативе, Шуберт - по заданню Гидрографического депо, Теннер представлял Топографический департамент, позднее Корпус военных топографов. Каждая работа имела свои задачи, преследовала свои обособленные цели. Единой нормальной меры не существовало: Струве пользовался «тоазом Фортэна», Шуберт - «условной саженью», Теннер - «линейкой Линнеля». Исходным пунктом геодези- 
ческих работ Струве была Тартуская (Юрьевская) астрономическая обсерватория, за исходный пункт триангуляции С.-Петербургской губернии Шубертом была принята обсерватория Академии наук в С.-Петербурге, в Балтийской триангуляции исходным пунктом служила обсерватория в г. Таллине. Все триангуляции были вычислены на сфероиде Вальбека. Однако нельзя сказать, чтобы между перечисленными трнангулящиями не было никакой связи. Обе триангуляции Шуберта и триангуляция Злобина привязаны к градусному измерению. Это объясняется как центральным положением дуги градусного измерения н высокой точностью этой работы, так и, конечно, личным участием в ней уже тогда знаменитого проф. В. Я. Струве.

Все перечисленные работы, за нсключением градусного измерения, малоточны. Средняя ошибка измеренного угла достигает \pm 2 ". Допусков не существовало. Измерения проводились, по выражению Шуберта, «с наивозможною точностыю:.

Указанный период интересен для нас как период исканий, совершенствования методов, приемов, инструментария, как период становления отечественной геодезии, период достижений, обогативших геодезическую науку. Три видных представителя этого периода (Струве, Теннер, Шуберт) шли в совершенствовании геодезической практики, теорин аппаратуры своим путем, используя все имеюшиеся достижения и внося все лучшее в сокровищнищу отечественной геодезической науки. Особо следует отметить заслуги В. Я. Струве. Предложенный им базисный прибор, использованный впервые в измерении базиса градусного измерения в районе пос. Симуна, заслужил признание и вошел в практику базисных нзмерений на долгое время. Велика заслуга Струве и в усовершенствовании геодезических инструментов. Замечательный наблюдатель и глубокий исследователь, ищуший все новые пути повышения точностн измерений, Струве предложил одновременно с Гауссом, но незавнсимо от него, новый метод измерения углов, метод многократного наблюденкя просгых углов. Әтот метод, под названием «метода академика Струве», употреблялся в первоклассной триангуляции до начала $\mathrm{XX}$ столетия и применяется сейчас в триангуляциях низших классов.

Известный интерес представляет отошедший теперь в нсторию, но тогда применявшийся способ определения долгот перевозкой большого числа хронометров. Хронометрические экспедиции представляли грандиозные предприятия. В первой русской хронометрической экспедиции, проведенной в 1833 году по предложению и под руководством Ф. Ф. Шу берта и имевшей целью связать по долготе основные астрономические пункты района Балтийского моря, приняли участие все страны, прилегающие к Балтийскому морю. В первой экспедиции было использовано 56 хронометров, было совершено шесть рейсов. Вся экспедиция продолжалась 115 дней. Способ определения долготы перевозкой хронометров состоял в неоднократном сравнении показаний хронометра определяемого пункта с показаниями перевозимых хронометров. На определяемых пунктах оборудовались временные обсерватории, на которых в течение всей экспеднции определялись время и широта. На территорию Эстонии приходилось три таких пункта. Не менее грандиозная по свонм масштабам была хронометрическая экспедиция, выполненная в 1843 году под руководством В. Я. Струве. Цель этой экспедиции - связать по долготе Пулковскую обсерваторию с Гринвичем. В работе было использовано 70 хронометров, совершено 16 рейсов. В 1854 году большая хронометрическая экспедиция была осуществлена между Пулковым и Тарту. 'Сухопутным путем перевозилось 34 хронометра, было сделано 10 рейсов. Краме больших хронометрических экспедиций, проводились 
и так называемые малые экспедиции, имевшие целью определение астрономических координат пунктов, не охваченных триангуляцией.

Определенне астрономической широты не представляло особых трудностей. Пользовались разработанным Струве способом наблюдения зенитных расстояний светил вблизи первого вертикала.

Работы этого периода представляют в основном только исторнческий интерес. Нам интересен этот период еще и тем, что именно здесь, на территории теперешней Эстонской ССР, зародилось величайшее начинание того времени - великое Русско-Скандинавское градусное измерение, не утерявшее своего значения и до настоящего времени в вопросе определения размеров и фигуры Земли. Работы этого периода преследовали единственную цель - обеспечение предстоящих топографических съемок опорными точками. Эту задачу они выполнили. Территория тогдашней Эстляндской и Лифляндской губерний была покрыта сплошной сетью триангуляций различных классов. Конечно, работы не отлнчались однородностью: наряду с градусным измерением, работой, не уступающей по точности современным требованиям, стояла такая малоточная работа, как Лифляндская триангуляция.

Мы привели некоторые особенности, характеризующие работы этого периода. Причина этих недостатков - отсутствие прочной базы в геодезической практике тогдашней отсталой царской России. Надо было ее создать, используя для этого имеюшийся у себя и за рубежом опьт; надо было приобрести опыт самим, расширить, усовершенствовать и применить к отечественным условням. Каждый из геодезнстов того времеши шел к достижению этой целн своим путем, внося свои достнжения в сокровищнищу отечественной геодезической науки. Результаты не замедлили сказаться. К середине XIX века Россия была уже одной из ведущих стран в этой области науки и практики.

Со второй половины XIX столетия и почти до начала девяностых годов трнангуляционные работы на территории Эстонской ССР не ведутся.

Второй период триангуляциянных работ начинается с 1892 года и охватывает конец дрошлого и начало настоящего столетия до Великой Октябрьской сощиалистической револющии. Это период расширения и углубления геодезнческой мысли и практики, подведения итогов в виде создания общеобязательных инструкций и наставлений, период систематизации работ и первых попыток создания общегосударственной схемы. Работы ведутся исключительно Корпусом военных топографов. И хотя работы этого периода как по методу выполнения, так и по времени должны были бы представлять одно целое, они все же образуют две триангуляции, основанные на различных эллипсоидах и вычисленные от разных исходных пунктов.

1) Триангуляция С.-Петербугрской н Эстляндской губерний, выполненная под руководством ген. Бонсдорфа в период $1888-1903$ годов, на территорни Эстонии велась с 1892 года. Триангуляция охватила всю северную часть материковой территории, острова и западные районы Эстонии вдоль Рижского залива; в пентральной части прошла по местам градусного измерения до г. Тарту. Исходным пунктом триангуляции явилась Пулковская обсерватория. Вычисления проведены на сферонде Кларка.

Голосом прошлого, нитью, связывающей тот период теодезических работ с работами настоящего времени, явилось письмо, найденное в бутылке при раскопке подземного центра пункта Варесмяэ в 1930 году. 
«Пусть она (бумага - Г. Ж.) послужит связующим звеном наших потомков с отдаленным прошлым и перекинет их мыслями в ту эпоху, когда мы душою и телом трудились на пользу и славу отечества и на развитие этого светлого дела и вносили, как пчелка мед, в эту прекрасную науку результаты наших практических работ. Потомство сравнит нх со своими и оценит по достоннству».

Да! Мы преклоняем голову перед славной плеядой русских геодезистов, самоотверженно служивших науке, много ценного внесших в нее и тем заложивших базу невнданному росту геодезической науки в нашей стране.

2) Триангуляция южной части территории Әстонии известна под названием триангуляции западного пограничного пространства. Сюда относягся: а) первоклассный ряд от Тарту вдоль градусного измерения до г. Якобпилс (Латвийская ССР) в 1903-1904 годах и б) ряд вдоль восточного берега Чудского озера (Пейпси) через Псков до соединения с триангулящией 1903-1904 годов в районе Выру-Валга (1907-1908). Одновременно велось сгущение сети триангуляций низших классов, продолжавшееся до 1912 года. Исходным пунктом этих триангулящий послужила Тартуская обсерватория. Основанием служил эллипсонд Бесселя.

Первой особенностью и большим недостатком работ этого периода является использование различных эллипсоидов и различных нсходных пунктов. Даже в каталогах того периода отразилась эта особенность: каталог южной Әстонни дан в Юрьевской системе [исходный пункт Тартуская (Юрьевская) обсерватория], каталог северной Эстонии вычислен в Пулковской снстеме. Координаты одного и того же пункта, данные в той или другой системе, различались на величнну, превышающую 100 метров. Это наличие двух систем явилось большим препятствием при сведе́нии карт, а также оказалось камнем преткновения при создании единой триангуляционной системы буржуазного периода.

Второй особенностью работ этого периода является наличие инструкций и параллельно нарушение последних по отдельным разделам. Инструкция 1899 года не выполнялась ни в части закладки центров, ни в части инструментов и методов измерения. Искали более совершенных, более точных способов и приемов, шла борьба за поднятие точности работ. Все нововведения инструкции 1910 года были выдвинуты практикой этого пернода: использование ночного времени для наблюдений, изменение способа закладки центров, изменение способа измерения горизонтальных углов - вот результаты этих исканий. Геодезические работы этото периода определили и некоторые особенности русской геодезической практики, сохранившиеся до наших дней (например, постройка сложных сигналов). В это время наметились и общие черты дальнейшего развития и организащни геодезических работ в России. И. И. Померанцевым была в 1910 году предложена схема построения государственной геодезической сети, развитая впоследствие проф. Ф. Н. Красовским в стройную и точную систему и претворенная в жизнь на необъятных просторах нашей Родины.

Второй период был сравнительно коротким, но тем не менее по объему проведенных работ весьма продуктивным. На территории нынешней Эстонской ССР развертываются триангуляционные работы всех классов, проводится топографическая съемка; вдоль основных магистралей прокладываются нивелирно-теодолитные и нивелирные ходы, ставятся астрономические и гравиметрические определения.

Если первый пернод был началом «возрождения» геодезической теории и практики, требующим от работников пионерского труда, то вто- 
рой пернод был уже периодом до некоторой степени проторенной дороги, периодом расширения и углубления теории и практики, периодом подведения итогов, создания наставлений и инструкций.

Конечно, триангулящии такой маленькой территории, какой является территория Эстонии, не могут дать истинной картины развития геодезической мысли и практики тогдашней России. Деление на периоды тоже весьма относительное, связанное именно с рассматриваемой терригорией. Но общий ход развития, полагаем, дан правнльно: отсталость в начале XIX века, затем прыжок вперед до уровня тогдашннх передовых стран, далее искание свонх путей, расширение и углубление знаний, создание отечественной геодезической школы в ограниченных условиях царской России, и, наконец, невиданный размах геодезических работ в советскую эпоху.

Территория теперешней Эстонской ССР была свидетельницей этих двух первых периодов развития отечественной геодезии. Третий период, самый богатый по своим достижениям, период советской геодезии, не мог, конечно, коснуться территории Эстонской ССР до 1940 года, года вступления Эстонни в братскую семью народов СССР.

C 1918 по 1940 год геодезическая практика Эстонии шла своим путем.

\section{III}

Развитие триангуляционных работ в буржуазной Эстонии носило на первых порах случайный характер. Для картографирования пограннчных районов в восточной части республики развивалась триангуляционная сеть младших классов. Исходными пунктами служили пункты русских триангуляций, координаты которых имелись в каталогах. Необходимость в обновлении морских карт потребовала развития первоклассной сети вдоль побережья Финского залива. Не имея ни специалистов, ни инструментария, Эстония обращается за помощью к своему северному соседу - Финляндии. Финский геодезист профессор Шенберг соглашается выполнить эту работу. Работа, длившаяся е 1921 по 1924 год, имеет значение лишь как школа подготовки молодых триангуляторов. Практнческого значения работа не имела, так как ни один треугольник не был замкнут. 1924 год ознаменовался вступлением Эстонии в члены Балтийской геодезической комиссии (БГК), выступившей с задачей определения фигуры геонда в районе Балтийского моря. C 1925 по 1935 год Әстония, выполняя программу геодезических работ БГК, прокладывает первоклассную сеть треугольников по островам и северозападному побережью до Таллина, связывает через заливы свою цепь с триангулящией Финляндии и Латвии, измеряет на своем участке два базиса (около г. Таллина и на о. Саарема) и проводит астрономические наблюдения на всех триангулящионных пунктах этого ряда.

В это же время продолжаются триангулящионные работы в северовосточной и юго-восточной частях республики с целью создания основы для картографнрования страны в масштабе 1:25000. Для обеспечения необходимой точности и здесь развиваются первоклассные сети. Северовосточная сеть развивается от первоклассных пунктов старой русской триангуляции Нарва и Вайвара, юго-восточная от пунктов Мунамяги и Меремяэ. Уместно напомнить, что русские триангулящии второго периода были даны в различных системах: северная - в Пулковской, южная - в Юрьевской. Развитие отдельных обособленных сетей триангулящий первого класса в северо-восточной и юго-восточной частях республики создало две самостоятельные системы, которые назывались «северная» и «южная». С развитием северной сети в западном направ- 
лении для нее было найдено в рамках БГК еще одно назначение: совместно с триангуляционной сетью Советского Союза и Финляндии опоясать Финский залив. Южная же сеть могла служить второй связью с латвийской триангуляцией.

К началу 1935 года создалось следующее положение: участок международной сети в течение текущего года должен был быть закончен; «северная» сеть продвинулась от восточной гранищы на запад до меридиана г. Тапа, а на юге приблизилась к г. Тарту; єюжная» сеть была доведена в северном направлении до Тарту, в западном - до г. Валга, в районе которого в 1933 году был измерен общий с Латвией первоклассный базис. Настал момент соединения триангуляций, назрела необходимость выбора единой системы координат. 1935 год явился годом переворота и на топографическом фронте работ. Съемка масштаба 1:25000 была признана слишком медленной, а потому было решено приступить к рекогносдировке старых карт в масштабе 1:50 000. Переход от съемки к рекогносцировке требовал быстрейшего продвижения триангуляционных работ и немедленного создания единой системы координат. Темпы триангуляционных работ за период с 1926 по 1934 год, т. е. за девять лет работ, были далеко не утешительные: сплошной сетью было покрыто не более одной трети всей небольшой территории.

Для расширения работ имелись благоприятные предпосылки: заканчивались работы на участке БГК, а следовательно высвобождались силы и инструментарий для работ в глубине территории; если до сих пор единственным производителем работ был Топографический отдел штаба эстонской армии, располагавший двумя первоклассными инструментами, то теперь вступал в работу и Кадастровый отдел Министерства сельского хозяйства, приобревший большой теодолит Вильда. Вместо двух инструментов стало три, из которых на теодолит Вильда возлагались болышне надежды.

C 1935 года трианғулящионные работы получают большой размах. В 1938 году первоклассная триангуляция Эстонии была закончена, территория республики полностью покрыта сплошной сетью первоклассных треугольников. В 1939 и 1940 годах привязываются два дополнительных пункта и устанавливается дополнительная связь эстонской сети с триангуляцией Латвин.

Астрономические определения были выполнены на всех пунктах эстонского участка международной сети и в единичных пунктах в глубине страны. Всего было определено 30 астропунктов. Астрономические наблюдения состояли из определения широты, долготы и азимута.

Эстонская первоклассная триангуляция 1926-1940 годов представляет сплошную сеть из 170 треугольников, базирующуюся на три базиса: северный (около т. Таллина), южный (в районе города Валга) и западный (на о. Саарема). Триангуляцией определено 118 первоклассных пунктов.

Работы выполнены по программе работ БГК, дававшей лишь основные положения для проведения работ и оставлявшей открытыми вопросы практического выполнения. Инструкция, притом также весьма неполная, появилась лишь в 1935 году.

Сперва полное отсутствие, затем неполнота появившихся инструкций в сочетании с недостаточной подготовкой исполнителей и отсутствием надежного руководства и контроля вызвали наличие кустарщины в проведении первоклассных работ. В работах используются первоклассные инструменты, но на их исследование не обращается внимания; принятый метод измерения углов (метод Бонсдорфа) не выдерживается до конца. Добросовестная, честная работа исполнителей дала бы другие 
результаты при более строгом контроле, при более серьезной теоретической подготовке триангуляторов, при ясном понимании ими предстоящих задач.

Отсутствие схем и перспективных планов развития триангулящионной сети во многом усложнило работу и значительно увелнчило объем измерительных работ.

Все эти причины, вместе взятые, имели результатом то, что выполненные измерения потеряли характер строгой научно-технической работы, каковой должна быть первоклассная триангуляция. Конечно, для практических нужд материалы измерений могли быть нспользованы, тем более что они удовлетворяли требуемой точности. Строгое же уравновешивание сети, в виду наличия неоднородного по точности измерительного материала, было значительно затруднено.

Уравновешивание, выполненное до 1940 года, носило предварительный характер и выполнялось по отдельным полигонам в порядке их нанизывания с учетом наличия поступающего измерительного материала. Была ясна одна цель - быстрее дать рабочне координаты пунктов в единой системе для нужд картографирования страны. Установление исходных данных так же не носнло научного характера. Координаты основного пункта были взяты из одного каталога, азимут с него на соседний пункт - из другого каталога, причем этот азимут был «случайнољ уменьшен на 1", 102. Вычисления проводились на эллипсонде Бесселя, прямоугольные координаты давались в проекции Гаусса-Ламберта.

В чем причина того, что триангулящнонные работы в буржуазный период развивались так бессистемно, так неорганизованно, на недостаточном научном уровне? Ведь в это же время за линией восточной границы бурно развивалась наука, ставшая подлинно народным достоянием, служившая благу своей сощиалистической Родине. Крепла, росла, стремительно развивалась советская геодезическая наука и практнка.

Буржуазное правительство Эстонии не было вообще заинтересовано в проведении точных работ. Проведение первоклассной триангулящии было навязано Балтийской геодезической комиссией, членом которой была и Эстония. Недооценивая важности научных и практических целей точных геодезических работ, не придавая им государственного значения, буржуазное правительство пустило развитие работ на самотек.

Итак, к геодезическим достижениям и работам Советского Союза Эстония смогла в 1940 году прнсоединить хоть и сравнительно обширный по объему, но не достаточно строгий в научном отношении материал полевых геодезических измерений.

Институт физики и астрономии

Академии наук Эстонской ССР

\section{ЛИТЕРАТУРА}

1. Г. Желнин, О базисе Струве в районе поселка Симуна ЭССР, Публ. Тарт. астр. обсерв., т. XXXII № 1, 1952.

2. Записки Военно-Топографического Депо (части, отдела), 1837-1946 гг.

3. Запнски гидрографического Депо, ч. I, 1835, ч. III, IV, 1836.

4. В. Я. С тр в е, Дуга меридиана в $25^{\circ} 20^{\prime}$ между Дунаем и Ледовитым морем, нзмеренная с 1816 по 1855 г., СПБ, 1861.

5. F. G. W. S truve, Beschreibung der von der Universität zu Dorpat veranstalteten Breitengradmessung in den Ostseeprovinzen Russlands, ausgeführt und bearbeitet in den Jahren 1821 bis 1831, Dorpat, 1831.

6. W. Struve, Resultate der in den Jahren 1816 bis 1819 ausgeführten astronomischtrigonometrischen Vermessung Livlands, S.-Petersburg, 1844. 